\title{
Decolonizing madness? Transcultural psychiatry, international order and birth of a 'global psyche' in the aftermath of the Second World War
}

\author{
Ana Antić ${ }^{\dagger}$ \\ Department of English, Germanic and Romance Studies, University of Copenhagen, Emil Holms Kanal 6, 2300, Copenhagen, \\ Denmark \\ Corresponding author. E-mail: ana.antic@hum.ku.dk
}

\begin{abstract}
This article offers a transnational account of the historical origins and development of the concept of 'global psyche' and transcultural psychiatry. It argues that the concept of universal, global psyche emerged in the aftermath of the Second World War and during decolonization, when West European psychiatry strove to leave behind its colonial legacies and lay the foundation for a more inclusive conversation between Western and non-Western mental health communities. In the second half of the twentieth century, leading 'psy' professionals across the globe set about identifying and defining the universal psychological mechanisms supposedly shared among all cultures (and 'civilizations'). The article explores this far-reaching psychiatric, social and cultural search for a new definition of 'common humanity', relating it to the social and political history of decolonization, and to the post-war reconstruction and search for stable peace. It provides a transnational account of a series of interlinked developments and trends around the world in order to arrive at a global history of the decolonization of mental health science.
\end{abstract}

Keywords: transcultural psychiatry; decolonisation; colonial legacies; global psyche; universalism; cross-cultural encounters

Can psychiatry be global? Are mental illnesses universal, and universally identifiable across the globe? Can the theories and methods of modern psychiatry be used to understand and alleviate the suffering of diverse groups of people from around the world? In the recent years, numerous critical voices emerged which have interrogated the viability of a global psychiatric nosology and challenged its current impulse to universalize primarily Western psychiatric categories and concepts of personhood. ${ }^{1}$

However, while criticisms of the globalization of psychiatry have compared Western psychiatric interventions to colonial projects, there has been little substantial analysis of the historical roots of the current global mental health movement. ${ }^{2}$ While the literature on contemporary global mental health issues is rich and contentious, it tends to assume that the concept of global mental health is a recent one and rarely engages with any aspect of its history. ${ }^{3}$ This article will argue that the

\footnotetext{
${ }^{\dagger}$ The research for this article has been funded by the ERC Starting Grant DECOLMAD, grant number 851871.

${ }^{1}$ Derek Summerfied, 'Cross-Cultural Perspectives on the Medicalization of Human Suffering', in Posttraumatic Stress Disorder: Issues and Controversies, ed. G. Rosen (Chichester: John Wiley and Sons, 2008).

${ }^{2} \mathrm{An}$ important exception here is Aidan Seale-Feldman, 'Historicizing the Emergence of Global Mental Health in Nepal (1950-2019)', HIMALAYA-The Journal of the Association for Nepal and Himalayan Studies 39, no. 2 (2020): $29-43$.

${ }^{3}$ L.J. Kirmayer and D. Pedersen, 'Toward a New Architecture for Global Mental Health', Transcultural Psychiatry 51, no. 6 (2014): 759-76; C. Mills and S. Fernando, 'Globalising Mental Health or Pathologising the Global South?', Disability and the Global South 1, no. 2 (2014): 188-202. Scholars have recently started to explore this aspect, most notably Anne Lovell, who 
concept of a global psyche and universal humanity actually emerged in the aftermath of Second World War and the Nazi atrocities and in the midst of decolonization, when Western psychiatry attempted to leave behind its colonial legacies and entanglements and lay the foundation for a more inclusive, egalitarian communication between Western and non-Western concepts of mental illness and healing. In this period, the infrastructure of post-colonial global and transcultural psychiatry was set up, and leading psychiatric figures across the world embarked on identifying, debating and sometimes critiquing the universal psychological characteristics and psychopathological mechanisms shared among all cultures and civilizations.

The article will explore how psychiatrists and anthropologists from all over the world engaged in a medical, social and cultural search for a new definition of 'common humanity' by attempting to re-define the relationship between culture, race and individual psyche. As the global crisis at the end of the Second World War was compounded by the escalation of colonial conflicts and the onset of decolonization, a large number of 'psy' professionals believed that peaceful cross-cultural communication and more harmonious global relations could only be ensured if they could determine how cultural environments shaped the basic traits of human psychology, and what universal characteristics were shared by all societies regardless of cultural differences. I will explore the multiple voices which took part in these discussions, arguing that participants from the Global South and Eastern Europe re-shaped the field in a crucial way and developed innovative approaches and conceptual frameworks in order to grapple with the profession's lingering colonial and racist aspects. The article explores how global psyche and universal humanity have served as key sites of re-drawing the boundaries of humanity in the second half of the twentieth century.

The emergence of a re-defined 'global psyche' at this time was tightly linked to the psychiatric profession's own efforts to decolonize - its clinical practices, intellectual frameworks and professional relationships. ${ }^{4}$ The historiography of decolonization has so far largely ignored psychiatry, while colonial psychiatry has received ample scholarly attention. ${ }^{5}$ Histories of post-colonial psychiatry remain limited to specific national contexts, although scholars have recently produced important historical analyses of the relationship between decolonization and psychiatry in Nigeria, Uganda and Senegal. ${ }^{6}$ This article offers a comparative transnational examination of these trends, linking them to the most important global political and social developments of the time. It explores how far post-Second World War global transcultural psychiatry succeeded in distancing itself from erstwhile colonial concepts and theoretical frameworks and analyses the intellectual continuities and ruptures in the profession's decolonization. The article will explore both the political significance and internal incoherencies of the universalist framework and examine how a variety of experts sought to develop responses to such contradictions, which superseded the universalist/relativist binary.

I will also relate this transformation to the process of post-Second World War reconstruction. The existing studies in transcultural psychiatry have only touched upon this important theme most importantly, Erik Linstrum has analyzed the role of British colonial psychologists in the development of utopian political agendas of international organizations such as the World

looks into the historical development of psychiatric epidemiology, and Harry Yi-Jui Wu, who focuses on the history of the WHO's engagement with the standardisation of psychiatry.

${ }^{4}$ Alice Bullard, 'Imperial Networks and Postcolonial Independence: The Transition from Colonial to Transcultural Psychiatry', in Psychiatry and Empire, eds. Sloan Mahone and Megan Vaughan (Basingstoke: Palgrave Macmillan, 2007).

${ }^{5}$ Mahone and Vaughan, Psychiatry and Empire; Megan Vaughan, Curing their Ills: Colonial Power and African Illness (Stanford: Stanford University Press, 1991); Jock McCulloch, Colonial Psychiatry and The 'African Mind' (Cambridge: Cambridge University Press, 1995).

${ }^{6}$ Matthew Heaton, Black Skin, White Coats: Nigerian Psychiatrists, Decolonization and the Globalization of Psychiatry (Athens: Ohio University Press, 2013); Yolana Pringle, Psychiatry and Decolonisation in Uganda (Palgrave Macmillan, 2019); Katie Kilroy Marac, An Impossible Inheritance: Postcolonial Psychiatry and the Work of Memory in a West African Clinic (University of California Press, 2019); Dagmar Herzog, Cold War Freud: Psychoanalysis in the Age of Catastrophes (Cambridge University Press, 2016). 
Federation for Mental Health (WFMH) or UNESCO and has linked it primarily to transcultural explorations in child psychological development. ${ }^{7}$ This article will expand on this work, arguing that the decolonisation of psychiatry was very closely related to what I will call utopian global psychiatry - a trend among Western psychiatrists in the 1940s and 1950s, who believed that psychiatry, as a science of the human mind with essential insights into human nature, was central to preventing war and violence, and eliminating prejudice and cross-cultural hatred. The post-war impulse to define afresh the fundamental traits of humanity regardless of cultural particularity ultimately served to 'help men to live [peacefully] with their fellows in one world'. ${ }^{8}$ The decolonization of psychiatry was thus inextricably connected to the post-war search for peace and crosscultural understanding.

The rise of ideological universalism and the attendant idea of 'world civilization' in the midtwentieth century has received significant scholarly attention in various fields. Scholars and historians of international relations have attempted to disentangle the complex relationship between post-Second World War cosmopolitanism and imperialism and have shed light on the importance of the rhetoric of 'world citizenship' for some of the most important twentieth-century international institutions. ${ }^{9}$ Paul Betts has explored the role of history writing in the implementation of this 'philosophy of universalism', focusing on UNESCO's 1950s History of Mankind project, which set out to create a new 'world history as a record of cultural interaction and cross-fertilisation'. ${ }^{10}$ The article engages with these debates by analysing the enormous role of global transcultural psychiatry in developing such notions of world citizenship and 'universal consciousness'.

There is, moreover, important scholarly literature which addresses critically the rhetoric of 'apolitical' technocratic development in the post-colonial era and examines the role of social sciences in the history of 'developmentalism'. ${ }^{11}$ Transcultural psychiatry has so far remained outside these analyses, even though it contributed crucially to development debates. Like other spheres of international development, transcultural psychiatry could be used as a lens through which to explore the changing relationship between the former colonial powers and the Global South. The article does that by examining how the profession's ideas of universal historical development, modernity and 'backwardness' - which it shared with the development paradigm affected its attempts to decolonize.

The article focuses on the history of transcultural psychiatry from its rise to exceptional social and political influence immediately after the war, to the late twentieth century, when it faced increasingly severe criticism from anthropologists. Ultimately, after the 1980s, the disciplines of anthropology and psychiatry parted ways in an important sense, and the influence of transcultural psychiatry within the global 'psy' sciences became significantly more limited. The article traces the 'rise and fall' of transcultural psychiatry, but it is not structured chronologically. Instead, it is divided into several thematic sections, which allow us to explore the central importance of concepts such as universalism, ethnocentrism and assumptions about the pathology or otherwise of cross-cultural encounters.

This article, moreover, aims to demonstrate how transcultural psychiatric expertise developed in different geographical and political contexts, and how these different trends might have interacted with each other to shape a global discipline. Because of that, it does not focus on a particular case study but explores a wide range of psychiatric and anthropological sources - conference presentations, research articles and monographs, research project descriptions and analyses. These sources cover broad geographical areas but are fundamentally connected with each other - the

\footnotetext{
${ }^{7}$ Erik Linstrum, Ruling Minds: Psychology in the British Empire (Harvard University Press, 2016).

${ }^{8}$ WFMH, Mental Health and World Citizenship (International Congress of Mental Health, London, 1948 ), 30.

${ }^{9}$ Glenda Sluga, 'UNESCO and the (One) World of Julian Huxley', Journal of World History 21, no. 3 (2010): 393-418; J. Pemberton, Global Metaphors (London: Pluto Press, 2011).

${ }^{10}$ Paul Betts, Ruin and Renewal (New York: Basic Books, 2020), 328.

${ }^{11}$ E. Manela and S. Macekura, The Development Century: A Global History (Cambridge University Press, 2018); Frederick Cooper and Randall Packard, eds. International Development and Social Sciences (University of California Press, 1998).
} 
article traces the activities, writings and conclusions of the most influential figures, organizations and research projects in transcultural psychiatry. These include some well-known personalities, such as Thomas A. Lambo, John R. Reese and Alexander Leighton, but also a range of experts whose lives and contributions were explored to a significantly lesser extent, or not at all, in the existing scholarly literature (e.g. Sudan's Tigani el Mahi, Yugoslavia's Vladimir Jakovljevic and Caslav Hadzi-Nikolic or India's Jaswanth Singh Neki). In their professional lives, these psychiatrists were linked to each other in myriad ways - through common research projects, regular participation in important transnational events and conferences, and membership in important international organizations - and they often developed their approaches in conversation with, or in explicit opposition to, one another

The article argues that global histories of transcultural psychiatry ought to include a much broader variety of voices than they have done so far. While the universalist framework, promoted in the established Western centres of knowledge production, aimed to engage experts from the decolonizing world on an equal footing with varying levels of success, they were far from passive recipients. Psychiatrists from the decolonizing territories in Africa and Asia were essential to the creation of global psychiatry's new post-colonial identity and regularly highlighted the political inconsistencies, internal contradictions and incomplete decolonization of their globalizing profession. Moreover, the article aims to write socialist Eastern Europe into the global geography of postwar psychiatry and medicine. Even though it would appear that Eastern Europe was not directly involved in the processes of decolonization, those medical and psychiatric practitioners from the socialist block who collaborated with the Global South critically intervened in decolonization debates. In their relationship with African and Asian countries, Eastern Europe worked on replacing the failed Western colonial project with a different model of socialist development, cooperation and technical assistance. ${ }^{12}$ In the context of transcultural psychiatry, East Europeans were not marginal actors - they engaged with both Western practitioners and the Global South, and their Marxist critique of colonialism and conceptualization of social (and socially engaged) psychiatry produced groundbreaking insights, and alternative articulations of psychiatric universalism based on direct connections between the 'second' and the 'third' worlds. The article thus offers a more inclusive framework for analysing the role of experts from the Global South and the socialist bloc, demonstrating that these 'peripheral' regions informed and transformed some of the core transcultural psychiatric concepts, and that such East-South interactions and knowledge exchange figured prominently in the development of a global medical field.

\section{The crisis of humanity and the emergence of utopian psychiatry}

In the final phases of colonial rule and during decolonization, a group of psy professionals and anthropologists from Western Europe and North America began to develop a new clinical and intellectual field - transcultural psychiatry. The new discipline was to develop a more inclusive framework, which would integrate non-Western mental health (and cultural) concepts, social structures and healing strategies, free the discipline from its colonial and racist assumptions, and promote a new platform for communication among cultures across the world, thereby fostering a transformed new generation of peace-loving 'world' citizens. It ambitiously sought to define a minimum of common humanity shared among all members of the species. Importantly, as early as 1948, a group of world-leading psychiatrists and anthropologists called UNESCO and WHO to fund 'cooperative surveys in national cultures' in order to 'look particularly for characteristics which hold promise as aids to world citizenship' - this research would be conducted under the auspices of the WFMH. ${ }^{13}$

\footnotetext{
${ }^{12}$ See, for instance, James Mark, Artemy Kalinovsky and Steffanie Marung, eds. Alternative Globalizations: Eastern Europe and the Postcolonial World (Bloomington: Indiana University Press, 2020).

${ }^{13}$ WFMH, Mental Health and World Citizenship (International Congress of Mental Health, London, 1948), 30.
} 
The end of the Second World War was marked by a genuine search for a new definition of common humanity to prevent hatred, conflict and absolute destruction. In particular, early post-war psychiatrists in the global North defined this historical moment as one of extreme, unprecedented crisis - of human relations and of civilization as a whole. The world was on the brink of a disaster, while a different and genuinely global psychiatry was necessary to alleviate the cataclysmic effects of pathologies and prevent the suicide of humanity. Psychiatrists were called to contribute to warding off the core challenges to post-war peace: the lingering influence and appeal of the fascist and Nazi ideologies throughout Europe, as well as the growing hostility between the two political-ideological blocks in the Cold War. As the director of London's Tavistock Clinic, John R Rees, opined a few years later, cross-cultural global psychiatry had an epidemic on its hands - an epidemic of prejudice, a 'psychological disorder of attitude' - which it needed to rein in and eradicate, after this 'killer disease' had 'disposed of six million people in Europe not so long ago'. ${ }^{14}$

In the immediate post-war political and medical discourses, psychiatry became a fundamental tool for ensuring international harmony, compassion and world peace. The summary of the WFMH's 1948 international congress on mental health and world citizenship urged mental health practitioners to explore whether the catastrophe of the 'Third World War can be averted' and whether 'the peoples of the world can learn to collaborate for the good of all'. ${ }^{15}$ Brock Chisholm, a Canadian military psychiatrist who became the first director general of the WHO, proclaimed dramatically that 'psychiatry must now decide what is to be the immediate future of the human race'. Furthermore, he stated that 'the role of the psychiatrist ... is not merely that of a healer but that of one who seeks the causes of fear, anxiety, prejudice and vicious passion, and works to eradicate those causes'. ${ }^{16}$ Post-war global psychiatrists saw their discipline as a tool for changing, and saving, the world. In a similar vein, mid-twentieth-century anthropologists tried to craft for themselves -and for their profession - 'the role of cultural intermediary, teaching peoples how to get along together, to learn from one another' without sliding into war and mutual hatred. ${ }^{17}$

Other institutions and disciplines contributed profusely to these debates. UNESCO attempted to re-define and promote the notion of world civilization and to re-frame how policy-makers and scholars thought about human or cultural differences, particularly with the debates around the drafting and passing of UNESCO's statements on race between 1950 and 1967. The original Statement on Race, authored mainly by North American anti-racist social scientists in 1950, aimed to re-define the then-dominant dominant categories for understanding human diversity and to move away from biological towards population-based (and socio-economic, psychological and cultural) conceptualizations of 'race'. In that sense, the UNESCO statements reinforced the belief, so prominent among transcultural psychiatrists of the time, that no fundamental, biologically determined distinctions existed between different racial groups - they truly '[celebrated] human biological unity'. ${ }^{18}$ Another UNESCO publication typically argued for the creation of 'a new humanism in which universality is achieved by the recognition of common values in the diversity of cultures'. ${ }^{19}$ This ambition to develop a new definition of humanity amongst cultural difference marked the rise of what Peter Mandler referred to as ideological universalism, but

\footnotetext{
${ }^{14}$ John R. Reese, 'Problems of Mental Health in Our Time', East African Medical Journal 37 (1960): 6.

${ }^{15}$ WFMH, Mental Health and World Citizenship, 47.

${ }^{16}$ G. Brock Chisholm, 'The Psychiatry of Enduring Peace and Social Progress (The William Alanson White Memorial Lecture)', Psychiatry 9 (1946): 3-20.

${ }^{17}$ Archive of the WHO, M4/180/12, 'World Federation for Mental Health, A Positive Change of Attitude: Note by Margaret Mead to Start Discussion', 1956; Peter Mandler, Return from the Natives: How Margaret Mead Won the Second World War and Lost the Cold War (New Haven: Yale University Press, 2013).

${ }^{18}$ Sebastián Gil-Riaño, 'Relocating Anti-Racist Science: The 1950 UNESCO Statement on Race and Economic Development in the Global South', British Journal for the History of Science 51, no. 2 (2018): 281-303.

${ }^{19}$ Interrelations of Cultures: Their Contribution to International Understanding (Paris: UNESCO, 1953).
} 
it also echoed the tensions which emerged between universalizing and particularist tendencies in mid-twentieth century global psychiatry and anthropology.

To these global anxieties about world peace, the 1950s and 1960s added what Europeans perceived as the extreme dangers of decolonization: not only the anti-colonial movements and their challenge to the colonial order, but also the radical social, political and cultural transformations brought about by the withdrawal of the colonial powers. The period of decolonization fostered an extraordinary sense of urgency when it came to assessing mental health risks to those former colonial subjects perceived to be trapped in the rapidly changing world. Note, for instance, the tone of despair in the words of Donald Mackay, a mission doctor in Northern Rhodesia, who urged the Western public to invest in better understanding the specifics of African psychopathologies in order to prevent a psychological/political disturbance of global proportions: 'We need men trained in psychiatry and steeped in African background to stem the tide of threatening maladjustment. We hear much of development - but where is there development so pressing as this' ${ }^{20}$ One of the fathers of transcultural psychiatry Edward Margetts similarly argued that more work was urgently needed to shed light on the various features of the 'African mind', primarily 'in view of the rapidity of emergence to self-government of the African people'. In his view, Western psychiatrists' incomplete understanding of African mentalities was a problem 'of international importance'. ${ }^{21}$

Psychiatric concepts remain central to the politics of humanitarianism and empathy: Didier Fassin and Richard Rechtman have argued that universalistic assumptions regarding trauma and traumatization became the language to validate victimhood - the legitimacy of one's suffering - in a global context, and to elicit transcultural empathy. ${ }^{22}$ This aspiration to invoke cross-cultural empathy also drove the post-war turn to universalism in global psychiatry - while colonial psychiatry insisted on fundamental differences between racial and ethnic groups in order to strengthen a global regime of inequality.

\section{Universalism}

In this section, the article explores the concept of psychiatric universalism as articulated and discussed by the most prominent transcultural psychiatrists of the post-war era, who sought to define the core parameters for a new, post-colonial discipline of transcultural psychiatry. These influential figures - John R. Rees, Ari Kiev, Alexander Leighton, Eric Wittkower and Julian Leff - held high-ranking positions in the leading international medical and psychiatric institutions and were the most outspoken champions of universalism in Western post-colonial psychiatry. They, however, rarely reflected on important continuities between post-colonial universalism and colonial psychiatric frameworks.

Throughout the late 1950s and 1960s, some of the leading global psychiatrists insisted on downplaying the importance of any cultural differences for psychiatric practice and nosologies. John Rees, head of the WFMH, argued that cultural differences merely formed a veneer of symptoms and expressions: 'May I say here that I have visited many countries in the world and I don't believe there are fundamental differences or basic differences between anything that I heard in Africa and the things you find in other countries, except naturally in the cultural determinants of some symptoms of illness'. ${ }^{23}$ In a similar vein, Ari Kiev authored a seminal volume on 'primitive psychiatry', in which he firmly established a core similarity between Western and non-Western

\footnotetext{
${ }^{20}$ Donald Mackay, 'A Background for African Psychiatry', East African Medical Journal 25 (1948): 2.

${ }^{21}$ Edward L. Margetts, 'Ethnopsychiatry in the Field: An Outline of the Anthropological Approach to the Study of Psychopathology and Mental Illness in African Natives', CCTA/CSA/WFMH/WGO Specialists Meeting on Mental Health, Bukavu (March 1958), 12.

${ }^{22}$ Didier Fassin and Richard Rechtman, The Empire of Trauma: An Inquiry into the Condition of Victimhood (Princeton: Princeton University Press, 2009), 6.

${ }^{23}$ WFMH, 'Africa: Social Change and Mental Health', Report PF a Panel Discussion Conducted in Conference Room No. 1, UN, New York (March 1959): 29-30.
} 
therapeutic practices in terms of their core concepts, the emotional involvement of both recipients and therapists, and the responses they aim to elicit or deliver. Kiev concluded that 'It seems not unlikely then that mental illness is manifested in certain basic structural mechanisms and processes that recur together with certain regularity in the different clinical syndromes, providing a substratum on top of which the different cultures impose differences in content'. ${ }^{24}$

In 1977, Arthur Kleinman famously critiqued such trends and called for a new cross-cultural psychiatry: he pointed to many conceptual problems and inconsistencies in what he called 'old transcultural psychiatry', which 'involved a breathless search through large amounts of data from different societies looking for "universals"'. Kleinman argued for a much larger role for anthropology in cross-cultural research of mental illness and warned against transcultural psychiatry's greater interest in universals than differences, and its employment of Western-developed and influenced cultural models of illness to the exclusion of anthropological and phenomenological accounts. ${ }^{25}$ While Kleinman's intervention was very perceptive, it is important to reflect on the political significance of transcultural psychiatry's search for universals at the expense of differences in the era of decolonization.

In many ways, the insistence on universals in post-war transcultural psychiatry at least partly served the purposes of extending the boundaries of humanity, and reinforcing transcultural empathy between Europeans and their former colonial subjects. Kiev's confirmation that it appears likely that most healers would agree about which individuals are in need of help. Symptoms of uncontrollable anxiety, depression and agitation would be recognized almost everywhere as evidence of disorder, as would such gross breaks of contact with reality as delirium or acute schizophrenia' reaffirmed that all partook in a common humanity regardless of their cultural background or preference for traditional healers instead of medical doctors. ${ }^{26}$

Most present-day critiques of global mental health focus in particular on the movement's problematic assumptions of universality of both mental distress and treatment and see those as signs of quasi-imperialist and Eurocentric attitudes towards the Global South. ${ }^{27}$ While universalism played a more complex political role in the aftermath of the war, post-colonial definitions of mental health 'universals' often resembled European concepts of the human mind/interiority/psychological life. This was not limited to psychiatry. While the UNESCO statements on race aimed to dismantle biological and eugenic racial typologies, and to 'shift away from Eurocentrism towards a world of separate but interrelated civilisations', they also arguably introduced an intellectual framework within which the Western (or White) norms of modernity and development remained dominant. $^{28}$ The statements' anti-racist ideas of cross-cultural unity and fundamental equality coexisted with, or even encouraged, Western interventionist modernization projects in the Global South and fostered perceptions of non-Western communities as 'backward', 'primitive' and in need of rescuing. ${ }^{29}$ In the context of universalist transcultural psychiatry, practitioners and activists struggled with similarly hierarchical conceptualizations of non-Western communities and their relationship to the global North and often continued to see the world in racialized terms of primitivism and backwardness.

Psychiatric universalism of the mid-twentieth century was ridden by internal inconsistencies, and it struggled very hard to shed the weight of racist colonial theories and paradigms. One of the most influential and long-lasting legacies of colonial ethnopsychiatry turned out to be its evolutionary interpretation of the psychology of non-Western peoples. It drew a straightforward line between 'primitive' civilizations and the 'childhood stage of humanity' - a common trope in more

\footnotetext{
${ }^{24}$ Ari Kiev, Magic, Faith and Healing: Studies in Primitive Psychiatry Today (New York: Free Press), 19

${ }^{25}$ Arthur Kleinman, 'Depression, Somatization and the New Cross-Cultural Psychiatry', Social Science and Medicine 11, no. 1 (1977): 3-10.

${ }^{26}$ Ibid., 461.

${ }^{27}$ Mills and Fernando, 'Globalising Mental Health or Pathologising the Global South?', 188-202.

${ }^{28}$ Betts, Ruin and Renewal, 319-20.

${ }^{29}$ Gil-Riaño, 'Relocating Anti-Racist Science', 302-3.
} 
progressive psychoanalytic and anthropological discourses as well, which saw the 'savages' of the non-White world as fascinating snapshots of humanity as it was before the onset of 'civilization'. As Freud's close associate and biographer Ernest Jones noted, 'it is possible that the conscious thinking of savages is more directly and extensively influenced by unconscious factors than is that of civilized people, just as is so with the child'. ${ }^{30}$ The 'infantilism thesis' - that 'primitive adults' shared mental traits with children from the civilized world ('imaginary understanding, magical thinking ... narcissism') - received a fair amount of criticism in the post-war years, but its core tropes, and in particular its tendency to understand African civilizations in a static manner within the evolutionary context, survived well into the post-colonial period. In 1960, John Collin Carothers, whose earlier elaborations on the nature of the African mind received angry responses from certain academic anthropological quarters (as well as support from leading thinkers such as Margaret Mead) ${ }^{31}$, opined that 'the African way of life is, with minor variations, the way that all mankind, including our own ancestors, is likely to have followed in the past'. ${ }^{32}$ The damning social and political implications of this theory of historical atavism were clear. If the 'African' was in fact a member of the same human family as Western Europeans but trapped on a completely different developmental level, one that Europeans allegedly inhabited centuries ago, this did not bode well for modernization attempts and political independence in the decolonizing world.

Even though Carothers' simplistic theorizing about African psyche and psychopathology was increasingly dismissed throughout the 1960s and 1970s, the evolutionary theory persisted in transcultural psychiatry in different guises. One of its more imaginative reformulations came from the writings of Britain's foremost cross-cultural psychiatrist and one of the leaders of the UK section of the International Pilot Study of Schizophrenia (IPSS) Julian Leff. The IPSS was a WHO-funded project, whose scope and ambition were unprecedented in global and transcultural psychiatry thus far: starting in 1966, it involved the establishment of nine field research centres around the globe and engaged in clinical and research work on patients diagnosed with schizophrenia. This massive operation aimed to explore whether schizophrenia might be a universal psychiatric category and how cultural differences affected the symptoms and experience of the disease, as well as to standardize diagnostic criteria, classifications and therapies. ${ }^{33}$ But the implications of the IPSS were much broader, as it was a milestone in the post-war search for universal dimensions of human psychology: it established transcultural psychiatry as a research and clinical field, attempted to engage non-Western researchers and clinicians on an equal footing for the first time, and developed research instruments and conceptual frameworks which crucially shape the current crosscultural psychiatric thinking. The UK and US centres took the lead in conceptualizing and administering the study and developing protocols for processing the results and interpreting their implications. ${ }^{34}$ In that sense, Leff's role was extremely significant, and he was also one of the most prolific IPSS participants, continuing to publish important research about its long-term legacies and effects of global psychiatry and social psychiatry/psychotherapy in Britain.

One of Leff's most prominent contributions is his theory, based in large part on IPSS materials and experiences, of the development and differentiation of 'languages of emotion'. In it, Leff argued that an extensive and differentiated vocabulary concerning emotional states is only characteristic for developed countries of the Western world. Leff indicated a 'scheme' of an

\footnotetext{
${ }^{30}$ Quoted in Joy Damousi, 'Geza Roheim and the Australian Aborigine: Psychoanalytic Anthropology During the InterWar Years', in Unconscious Dominions: Psychoanalysis, Colonial Trauma, and Global Sovereignties, eds. Warwick Anderson, Deborah Jenson and Richard Keller (Duke University Press, 2011): 75-95.

${ }^{31}$ 'Carother's Study on Mental Health in Africans', Archive of the WHO, M4/445/13, 1953; for a Detailed Summary of Carothers' 'The African Mind in Health and Disease', published in the WHO Monograph Series in 1953, see also Linstrum, Ruling Minds, 198.

${ }^{32}$ J.C. Carothers, 'Further Thoughts on the African MIND', The East African Medical Journal (June 1960).

${ }^{33}$ N. Sartorius, R. Shapiro, M. Kimura and K. Barrett, 'WHO International Pilot Study of Schizophrenia', Psychological Medicine 2, no. 4 (1972): 422-5.

${ }^{34}$ World Health Organization, Report of the International Pilot Study of Schizophrenia, vol. 1 (Geneva: WHO, 1974).
} 
'evolutionary process in the dawning awareness of the psychological experiences of unpleasant emotion', according to which he classed most non-Indo-European languages as 'living fossils', left at an earlier stage of social and psychological development. ${ }^{35}$ Speakers of these languages, according to Leff, normally 'lacked words for depression and anxiety and instead [possessed] words for the bodily experiences of emotion which are relatively undifferentiated'. ${ }^{36}$ Leff s scheme was based on the idea of a linear historical process in the course of which people's consciousness of their own psychological experiences developed and grew ever more sophisticated.

Even though Arthur Kleinman praised Leff for his supposedly 'straightforward critique of ethnocentrism', Leff's linear interpretation remained not unlike the earlier, colonial version of evolutionary theory. It explicitly placed the non-Western world in an altogether separate historical stage of linguistic and psychological development and further argued that in traditional societies, where the 'cultural focus' was on the group rather than individual, 'there is little opportunity to explore the emotional aspects of relationships .... In traditional societies, where relationships are more or less stereotyped, emotions remain unexplored and undifferentiated' ${ }^{37}$ The move towards the individual in the West, on the other hand, was the main 'motive force behind the increasing differentiation of emotions and the expansion of the lexicon of emotions to allow the new refinements of experience to be communicated'. In other words, Leff's reading of IPSS materials portrayed 'Western' minds as more complex and sophisticated, as a result of long-term social and cultural historical processes, which possessed an 'incalculable momentum' compared to the developing societies. Colonial psychiatrists and psychoanalysts often ascribed extreme psychological simplicity and lack of differentiated personalities to Asians and Africans. In actual fact, Leff appeared to argue that the IPSS findings in the field research centres outside the Western world (such as in Colombia, Nigeria and India) confirmed those earlier theories.

Leff's theory was not a far cry from psychiatrists Benedict and Jacks' 1954 conclusion that the clinical picture of 'primitive' psychosis was 'a poor imitation of European forms' due to its lack of richness and complexity. ${ }^{38}$ Leff's evolutionary take, moreover, was not significantly different from Carothers' 1960 speculation about the sociocultural evolution of human societies, from the illiterate ('preliterate') beliefs in the unity of word ('verbal thought') and action, to the modern Western understandings that words in themselves could only have an effect on minds of others but not on the outer world. In 'primitive' societies, according to Carothers, 'verbal thoughts are seen as having power in the real world in their own right', which fundamentally shaped the mental universe, so that all thinking and acting became constrained along communal and social lines, and 'man becomes incapable of creative speculation on personal lines'. It was only in modern literate societies and after the rise of print cultures that 'the individual ... always comes to be regarded, and to regard himself, as capable of thinking for himself, as being potentially unique at the level of ideation and of will'. ${ }^{39}$ For Carothers, as for Leff, modern societies were unique, even revolutionary, precisely because they allowed for individualized (and automatically more nuanced) forms of thinking, speaking and feeling, which allowed for richer emotional and psychological vocabularies and thought registers.

Leff's contention soon came under criticism from anthropologists, as an excellent example of what Arthur Kleinman later referred to as a 'category fallacy' - an assumption that mainstream psychiatric categories were not highly culturally specific products of Western epistemologies and worldviews but expressed something of the universal core of mental illnesses, and that those same categories and diagnoses could be recognized in other parts of the world, hidden under layers of

\footnotetext{
${ }^{35}$ Julian Leff, 'Culture and the Differentiation of Emotional States', British Journal of Psychiatry, 123, no. 574 (1973): 299-306.

${ }^{36} J u l i a n$ Leff, Psychiatry Around The Globe: A Transcultural View (New York and Basel: Marcel Dekker, 1981), 45-6.

${ }^{37}$ Ibid., 72 .

${ }^{38}$ P.K Benedict and I. Jacks, 'Mental Illness in Primitive Societies', Psychiatry 17 (1954): 377.

${ }^{39}$ J.C. Carothers, 'Further Thoughts on the African Mind', The East African Medical Journal (June 1960), 461-2.
} 
cultural modifications and specificities. Indeed, Leff took a Western list of emotional concepts to non-Western communities, and concluded, unsurprisingly, that they had a less differentiated set of terms for those concepts than the English language. The fallacy was, however, in the next step in Leff s argumentation: this did not necessarily mean that individuals in those communities were themselves less psychologically differentiated or emotionally sophisticated, but that their definitions and experiences of selfhood may have differed significantly from the Western model, and that their 'languages of emotions' likely focused on a different range of internal mental states. ${ }^{40}$ The transition from somatic to psychological expressions of distress, moreover, should not always be read in an evolutionary context: according to Kleinman's research, China experienced a reverse process after the Cultural Revolution, when psychological expressions became less politically salient and were replaced by physical, somatic idioms of psychological suffering. ${ }^{41}$

Importantly, even though the 'somatization' hypothesis was often discussed and tested by a variety of psychiatric and anthropological experts, it was striking that Leff chose to interpret it almost exclusively in the context, and as a result, of cultural differences and specificities. As Roland Littlewood has subsequently argued, such reductive cultural explanations '[oversimplified] the multifactorial aetiology of the diseases studied'. ${ }^{42}$ In the specific case of reported tendencies in developing societies to explain psychological distress in terms of physical rather than experiences, Leff's decision to revive colonial psychiatry's evolutionary framework was at least partly determined by his reluctance to address any non-cultural factors which might explain the IPSS's curious results. Discussing the same issue in the context of his ethnological and clinical research in Uganda, anthropologist and psychiatrist John Orley has argued similarly that a tendency to frame distress in the 'language of body illness' often stems from the patient's 'desire to express his illness in what he thinks are terms acceptable to western medicine'. ${ }^{43}$ British psychologist Bal similarly emphasized the sociological background of patients and the social context of psychiatric consultation, arguing that 'working-class Asian patients are likely to use a mode of communication [physical complaints] which they believe will be acceptable to the doctor, and one which does not involve blaming family members for their distress' ${ }^{44}$ Moreover, in her examinations of Punjabi patients in Bedford, anthropologist and cross-cultural psychotherapist Inga-Britt Krause concluded that such somatic symptoms '[embodied] complex relations between external events, subjective experiences and personal selfhood, autonomy and control'. ${ }^{45}$ In other words, they were no less sophisticated than Western expressions of emotional distress.

Therefore, even though post-war transcultural psychiatry attempted to interpret cultural differences and their psychological effects in a more open-minded and egalitarian manner, its emphasis on predominantly cultural explanations often resulted in the exoticization and reification of (vaguely defined) cultural factors, which supposedly shaped non-Western societies in decisive ways. Despite the proclaimed psychiatric universalism and its tendency to disregard the importance of cultural differences as merely occluding the universal core of illnesses, leading figures such as Leff paradoxically focused on perceived cultural and civilizational distinctions as essential determinants of mental health experiences, often missing an opportunity to explore broader sociological and economic circumstances which shaped the lives and experiences of both Western and non-Western patients.

\footnotetext{
${ }^{40}$ F.R. Myers, 'Emotions and the Self: A Theory of Personhood and Political Order Among the Pintupi', Ethos 7 (1979): $342-70$.

${ }^{41}$ Arthur Kleinman, Social Origins of Distress and Disease: Depression, Neurasthenia and Pain in Modern China (New Haven: Yale University Press, 1986).

${ }^{42}$ Roland Littlewood and Maurice Lipsedge, Aliens and Alienists (London and New York: Routledge, 1982), 269.

${ }^{43}$ John H. Orley, Culture and Mental Illness: A Study from Uganda (East African Publishing House, 1970), 50.

${ }^{44}$ S.S. Bal, 'Psychological Symptomatology and Health Beliefs of Asian Patients', in Clinical Psychology: Research and Developments, ed. H. Dent (London: Croom Helm, 1987), 101-10.

${ }^{45}$ Inga-Britt Krause, 'The Sinking Heart: A Punjabi Communication of Distress', Social Science and Medicine 29 (1989), $563-5$.
} 
This particular trend had a long history in the profession: Western transcultural psychiatrists often insisted on cultural and ethnic specificities at the expense of other social factors - such as class or poverty - which played an important role in shaping both Western and non-Western conceptualizations of mental health and illness. Following Eric Wittkower's presentation about 'recent developments in transcultural psychiatry' at the CIBA Congress in 1965, which gathered all the most important figures in the field, a few audience members questioned his omission of any substantial discussion of the importance of sociological categories - class, education, age, gender, occupation - in cross-cultural psychiatric and anthropological research. As Alexander Leighton pointed out in his response, in Western multicultural societies such as Canada or the US, social class and other social categories played a very important role in mental health research. However, as Wittkower's presentation and curt responses illustrated, when it came to non-Western societies, transcultural psychiatry often tended to focus on cultural, racial and ethnic traditions, mores and specificities, essentializing and reifying them in the process, and failing to establish some common sociological or economic categories of analysis of Western and non-Western 'mentalities' ${ }^{46}$

This was not strictly limited to the West European psychiatric profession: one of the most important African psychiatrists of the time, Gambia's Emmanuel Foster, wrote a long and informative treatise on mental health practices and values in Ghana, the country in which he practised and focused on the complex psychological profiles of 'Africans in transition' - those Ghanaian patients whose everyday lives and value systems were disrupted by the massive social, economic and political changes tied up with the onset of independence, modernization and industrialization in West Africa. Foster's account was multifaceted and nuanced in parts, but his conclusion effectively marginalized the etiological significance of these factors, and stated that 'as a broad base line, the African's psychological illness is [primarily] linked to his peculiar beliefs in withcraft, juju, superstitions, and the all-powerfulness of the supernatural'. It naturally followed from this, moreover, that any psychiatrist or psychotherapist who had 'some understanding of the cultural background of the patients,... their superstitions, beliefs and fears' should be able to practice with effectiveness and success in African mental health settings. ${ }^{47}$ It was this particular kind of 'traditional' cultural knowledge that was deemed essential here, rather than any deeper familiarity with the rapidly changing social and political conditions in Ghana. As we will see below, it was in the decolonizing territories that important challenges arose to such a reifying conceptualization of 'cultural difference'.

\section{Responses from the decolonizing world}

In their innovative analyses of the history of human rights during the Cold War and decolonization, Steven Jensen and Roland Burke both highlight the importance of political actors from the Global South in promoting the universalist approach to human rights, while politically malicious cultural relativism was reserved for West European proponents of colonial rule. Arguing against the notion that international human rights were necessarily a Western (and Western-centric) imposition in the decades after the Second World War, these authors explored how politicians and activists from the decolonizing world - temporarily - embraced the language of universality and employed it for their own political purposes. ${ }^{48}$ Importantly, this argument extends beyond the

\footnotetext{
${ }^{46}$ The Ciba Foundation Symposium on Transcultural Psychiatry (London, 1965), Wellcome Collection, K36650, Wittkower, 'Recent Developments in Transcultural Psychiatry', 4-25. For a particularly forceful insistence on the primacy of narrowly defined cultural factors, see Edward Margetts, 'Ethnopsychiatry in the Field: An Outline of the Anthropological Approach to the Study of Psychopathology and Mental Illness in African Natives', CCTA/CSA/WHO/WFMH Specialists Meeting on Mental Health, Bukavu (March 1958), 1-12.

${ }^{47}$ Emmanuel Foster, 'The Theory and Practice of Psychiatry in Ghana', American Journal of Psychotherapy 16, no. 1 (1962): $7-51$.

${ }^{48}$ Steven Jensen, The Making of International Human Rights (Cambridge: Cambridge University Press, 2016); Roland Burke, Decolonization and The Evolution of International Human Rights (Philadelphia: University of Pennsylvania Press, 2013).
} 
field of human rights law-making and advocacy. In a comparable process, psychiatrists from the decolonizing world appropriated and adapted the meaning of 'universal psyche' in order to counter the evolutionary and hierarchical logic of colonial psychiatry, while nuancing the profession's universalist claims and advancing a unique critical analysis of its Eurocentric tendencies.

Indeed, non-Western researchers and psychiatrists struggled with the universalist paradigm the most and strove to emphasize its value in countering colonial hierarchies while grappling with its Western ethnocentrist tendencies. These researchers' contributions analysed in this section were all explicitly aimed at international audiences - as speeches and presentations delivered at key international conferences, research articles published in leading international journals, or research grant proposals addressed to international funding organizations. They exemplify the most influential and innovative interventions, through which non-Western clinicians and practitioners engaged critically with the Eurocentric aspects of the universalist paradigm and attempted to develop alternative conceptualizations of the relationship between Western and non-Western mental health traditions. ${ }^{49}$

In order to counter racist colonial psychiatry's notions of hierarchical fundamental difference between Europeans and the 'African mind', Nigeria's most important psychiatrist Thomas A. Lambo aimed to 'produce research arguing for the basic universal similarity of human psychology, irrespective of race, religion, ethnicity or geography'. ${ }^{50}$ Starting with his dissertation research at the University of Birmingham, Lambo identified Carothers' arguments about the biologically determined inferiority of the 'African mind' as particularly harmful for the development of cross-cultural psychiatry, and 'dangerous to scientific thinking' in general. Lambo endeavoured to prove unfounded Carothers' claims that 'African backwardness and the occurrence of "primitive psychosis" can well be linked to frontal idleness' and used his schizophrenia research on the Yoruba people in Nigeria to demonstrate that 'the nature of men is the same, what divides them is their custom'. While Lambo was everything but ignorant or dismissive of the myriad cultural nuances relevant to psychiatric research in Africa, his argument in favour of universality hinged on the idea that mental distress in Africa and in the Western world shared fundamental mechanisms which could be explained 'in terms of common psychodynamic formulations' ${ }^{51}$ The political implications of Lambo's work underscored the liberal and progressive origins of such psychiatric universalism in the decolonizing territories.

However, non-Western psychiatric practitioners threaded a thin and sensitive line between humanistic universalism, which could easily veer into a reinforcement of Eurocentric models of the mind, and insistence on the importance of culturally specific influences, a viewpoint that at times seemed dangerously close to colonial ethnopsychiatry. Facing this problem, Tigani El-Mahi, the legendary Sudanese psychiatrist, insisted more forcefully on the significance of culturally specific value systems and traditions: in his talk at the WFMH's meeting dedicated to social and cultural change in Africa, he insisted that 'a mental health worker must ... support the values of his community and of his day, and he must not act as a rebel.... in order to be a good worker for the community, you must love that community and you must love its culture. Out of our love for our culture, we have been able to understand that many of the demoniacal states, the

\footnotetext{
${ }^{49}$ The most influential critique of colonial psychiatry and its harmful political and psychological consequences was, of course, developed by Frantz Fanon. His incisive analyses of the psychopathology of colonialism shaped generations of post-colonial thinkers, and testified to the tight link between mental health and the political context of imperialism. But it is my sense that Fanon's fascinating oeuvre and influence remain outside the scope of this article - precisely because his intervention went well beyond the transcultural psychiatric discussions about universalism, cultural difference and ethnocentrism, focusing on much broader issues, whose significance could not be done justice in the article. In many ways, Fanon was outside the regular knowledge networks of transcultural psychiatry, an outsider who was larger than the profession itself, and only in that sense, and not in terms of his relevance, is he outside the scope of this research.

${ }^{50}$ Heaton, Black Skin, White Coats, 52.

${ }^{51}$ Thomas A. Lambo, 'The Role of Cultural Factors in Paranoid Psychosis Among the Yoruba TRIBE', The Journal of Mental Science 423, no. 101 (1955): 239-66.
} 
possessional states, have extremely valuable therapeutics for the patient himself ... a really therapeutic basis". ${ }^{52}$ Moreover, he warned Western practitioners that 'psychiatry is inseparable from the community and must follow it as a shadow'. This meant that, if a therapist was to be successful, he or she needed to be in agreement with patients on the causes and treatments of mental distress: for a psychotherapy to be effective in any culture or society, it needed to provide an aetiological theory which could be in line with the sociocultural context/assumptions and accepted by the society at large. It was only in such a culturally sensitive and nuanced context that positive psychological responses could be expected from (psychiatric) patients. ${ }^{53}$

For instance, El-Mahi testified to the inapplicability of psychoanalytic methods and frameworks to his clinical practice: 'the gulf between the therapist and the patient is so wide and their concepts as to what constitute illness and recovery so different, that rapport necessary for the opening phase of treatment never occurs'. This was similar to Lambo's message to his colleagues to 'decontaminate themselves intellectually from Freudian and neo-Freudian theories', which represented 'at their best a spectrum of possible ideas emanating from Hellenic and Judaeo-Christian culture and tradition', and were not particularly helpful when dealing with mental patients from different cultural traditions, or when describing their psyches and psychological processes. At the same time, El-Mahi explained the sociocultural aspects of Africans' psychological experiences and problems in terms thoroughly understandable to the Western audiences: discussing mental health problems in post-colonial Africa in terms of the rationality and utility of traditional 'primitive' beliefs and practices, in terms of a detribalizing Africa's 'quest for identity', and even used Erich Fromm's concept of 'fear of freedom' to discuss contemporary mental health problems of his patients. Both psychiatrists thus combined universalist conceptual frameworks with careful calls for culturally nuanced awareness and sophistication.

Moreover, throughout his career, El-Mahi insisted on an alternative conception of modernity, psychiatry and individuality, one that was not exclusively related to the European and Western worlds. In the context of post-war transcultural psychiatry, the issue of cultural differences and possible incompatibilities between different societies and 'civilizations' could potentially be bridged if some of the core terms of the debate were re-formulated, so that the most important concepts in modern psychiatry, psychology and medicine could be seen as legacies of both Western and non-Western cultures. Importantly, it was mainly psychiatrists, psychologists and anthropologists from the decolonizing world which developed such arguments. Egypt's leading psychologist Yusuf Murad, who was instrumental in the establishment of the country's postcolonial discipline of psychology, worked on the project of '[recuperating] ... the Arabic tradition as part and parcel of the history of the human sciences', and of relating contemporary scientific and medical discourses to earlier Arabic literature. ${ }^{54}$

Pushing against both colonial hierarchical thinking and post-colonial patronizing references to backwardness and primitivism, El-Mahi urged his colleagues to see Africans as 'adult humanity conscious of its own wisdom, penetrated by its own universal philosophy'. He discussed the extreme importance of African and Islamic contributions to the development of contemporary medical knowledge, tracing the emergence of concepts such as mental health, therapy and the unconscious in earlier non-Western settings. Moreover, El-Mahi detailed the rise of the notion of 'medicine as a social institution' in the Arabic culture - the notion which certainly marked Western medicine and public health in the middle of the twentieth century - and linked contemporary medical theories of aetiology, cause and treatment to their origins in the works of ancient

\footnotetext{
${ }^{52}$ WFMH, 'Africa: Social Change and Mental Health', Report of a Panel Discussion Conducted in Conference Room No. 1, UN, New York (March 1959), 20.

${ }^{53}$ Tigani El-Mahi, 'Concept of Mental Health', East African Medical Journal 37, no. 6 (1960), 472-7.

${ }^{54}$ Omnia El-Shakry, 'The Arabic Freud: The Unconscious and The Modern Subject', Modern Intellectual History 11, no. 1 (2014): 109.
} 
Egyptian and medieval Islamic thinkers. ${ }^{55}$ In that sense, El-Mahi diversified the very history of medicine and psychiatry, drawing attention to these disciplines' cross-cultural origins and making it difficult to imagine a world where communication was impossible due to sharp cultural and civilizational boundaries. The experimental combination of modern psychiatry, psychoanalysis and traditional healing at the Fann hospital in Dakar, for instance, was not an attempt to merge radically different, possibly incompatible cultural traditions, or to pull backwards the achievements of Western medicine. On the contrary, as Katie Marac-Kilroy suggested, it was a project of building a distinctly Senegalese modernity, whose different aspects were not alien to the Senegalese culture, nor could they be reduced to Westernization. ${ }^{56}$

In an imaginative effort at squaring the circle of transcultural psychiatric exchange, a group of psychiatrists from New Delhi's All India Institute of Medical Sciences followed the same logic and explored multicultural origins and complex traditions of modern psychotherapy. ${ }^{57}$ Even though they argued that orthodox Western psychotherapy could not simply be imported as a '[piece] of hard technology' to different cultural environments, they rejected the notion that psychotherapy as a concept was new or alien to India, and that the practice of psychotherapy had to be taught by Westerners as part of some concept of technological development. Quite to the contrary, these psychiatric professionals believed that psychotherapy 'in a general sense' was autochthonous to the Indian society - India produced ancient systems of belief and practice, such as Buddhism, Vedanta or Yoga, which were centrally concerned with the attainment of personal liberation and alleviation of suffering, and which aimed to affect people's consciousness and social relations. As such, the Indian psychotherapeutic systems played a vital role in shaping the global history of psy disciplines, but they were also central to the future of transcultural psychiatry and to its universalization.

Namely, traditional Indian psychotherapy was concerned with 'suffering' as a generality, as afflicting all of mankind, and not essentially as a particularity, as the particular affliction of a given patient', like in the Western clinical system. ${ }^{58}$ Such universalist tendencies could provide a way out of an impasse for contemporary Western psychotherapy, which was reportedly overly narrow and focused on individual patients, as isolated from their broader surroundings. Since the Western individualist clinical psychotherapeutic system was now in the midst of a severe crisis, 'Eastern psychotherapies' were best placed to offer a 'universal framework for which [Western psychiatrists] now seem to be groping. ${ }^{59}$ In that sense, authentic non-Western psychotherapies needed to be written not only into the history but also into the future of psychotherapy. While transcultural applications of Western systems were most likely to be futile, 'the future of psychotherapy, whether in the East or the West, is likely to be the same'. Here again, psychiatrists from outside the Western centres affirmed the idea that a truly transcultural psychiatric practice is only possible because psychotherapeutic traditions were not confined to the West European world, and the new discipline of cross-cultural psychiatry involved a genuine two-way exchange of expertise and experiences.

Such explorations of non-Western origins of psychiatric philosophies and practices were a supremely important contribution to the post-colonial global conversation. In addition to these arguments, some non-Western transcultural psychiatrists developed another approach to counter the essentialization of cultural difference in psychiatric discourses and insisted on the importance of sociological and socio-economic analysis instead of focusing on exclusively cultural interpretations of mental distress. In a 1975 interview with Philip Singer, Lambo argued passionately in

\footnotetext{
${ }^{55}$ Tigani El-Mahi, 'Concept of Mental Health', East African Medical Journal 37, no. 6 (1960): 472-7.

${ }^{56}$ Katie Kilroy-Marac, 'Nostalgic for Modernity: Reflecting on the Early Years of the Fann Psychiatric Clinic in Dakar, Senegal', African Identities 11, no. 4 (2013): 367-80.

${ }^{57}$ J.S. Neki et al., 'Psychotherapy in India: Past, Present and Future', American Journal of Psychotherapy 29, no. 1 (1975): 92-100.

${ }^{58}$ Ibid., 95.

${ }^{59}$ Ibid., 98.
} 
favour of working with traditional healers, depicting them as promoters of social psychiatry in the African world: 'And this, in fact, is one of the tremendous human qualities of the traditional healers. That they can listen, they really have tremendous interest, emotional empathy, and relationship'. ${ }^{60}$ In his other writings and research, Lambo emphasized the importance of conceiving of African patients as 'social beings' (rather than representatives of alien and illegible cultures). He viewed 'the new medical problems of Africa' as a purview of social medicine and social psychiatry primarily, calling for the 'establishment of a complete social morphology and a more refined analysis of the complex life of African social institutions', instead of simply accepting that psychological problems of Africans stemmed from a clash of traditional societies/individuals with some incompatible European values. ${ }^{61}$ In a similar vein, the University of Ibadan's Department of Psychiatry submitted a funding application for a local project focused on schizophrenia research among Africans and only proposed to explore the 'high rate of population growth, increased mobility of the population, rapid socio-economic change [and] the changing age structure' as the core factors contributing to an growing incidence of schizophrenia in the developing world. ${ }^{62}$

\section{Western ethnocentrism}

Very early on, involved intellectuals such as Margaret Mead spoke of American psychiatry's 'imperialism' and 'egocentrism', critiquing the psychiatric profession's tendency to impose its rigid interpretations and diagnoses on non-Western phenomena and behaviours. ${ }^{63}$ But it is indeed striking how rarely mental health professionals suggested, even in the subsequent decades, that Western psychiatry might be seen as merely another form of ethnopsychiatry, and that forms of behaviour considered 'normal' or average in Western civilization could be deemed pathological in non-Western societies. Taiwanese psychiatrist Pow Meng Yap's conclusion - that 'many primitives would, according to their own standards and values, regard as diseased or abnormal certain forms of behaviour, which are in the West only regarded as personality aberrations or, indeed, as entirely normal personality and character traits' - was surprisingly uncommon in the context of post-war transcultural psychiatry. ${ }^{64}$

In this section, the article explores the writings of those leading transcultural psychiatrists, such as Yap himself, but also G. Allen German and John Orley, whose contributions to the profession were primarily marked by their nuanced, anthropologically informed understanding of the complexity and importance of non-Western systems of knowledge, and their willingness to decentre Western cultural and medical paradigms. Even these psychiatrists - despite their ethnographic sensitivity, and subtle and inclusive definitions of 'culture' and cultural difference - ultimately accepted the precedence of Western psychiatric practice and theory over all other epistemological models. The most important intellectual challenges to such hierarchical interpretations did not, therefore, come from these psychiatrists, but from two rather separate corners: Western anthropologists and adherents of the 'new transcultural psychiatry' in the 1980s, and Marxist psychiatrists from Eastern Europe.

Even as he was calling for a more Africa-centred approach and for viewing traditional healers and 'witchdoctors' as comparable to social phenomena in Western cultures, Uganda-based

\footnotetext{
${ }^{60}$ Philip Singer, 'Traditional Healing and Medical/Psychiatric Mafia: Exclusive Interview with T.A. Lambo M.D., Deputy Director-General, WHO', in Traditional Healing: New Science or New Colonialism, ed. Philip Singer (Owerri, New York, London: Conch Magazine Limited, 1977).

${ }^{61}$ Thomas A. Lambo, 'The Concept and Practice of Mental Health in African Cultures', East African Medical Journal 37, no. 6 (1960), 464-71.

${ }^{62}$ Archive of the University of Ibadan (Faculty of Medicine), COMED 10-20-31, Request for Grant from WHO, Geneva, January 1965.

${ }^{63}$ Margaret Mead, 'The Mental Health of Mankind', The Lancet, 252, 298.

${ }^{64}$ P.M. Yap, 'Mental Diseases Peculiar to Certain Cultures: A Survey of Comparative Psychiatry', Journal of Mental Science 97 (1951): 313-27.
} 
psychiatry professor G. Allen German did not understand them as culturally specific alternatives to Western psychiatric medicine but as akin to 'backstreet abortionists' and priests. In his otherwise informative and culturally sensitive study of conceptualizations of illness in Uganda, Orley expressed scepticism about involving traditional healers in psychotherapeutic processes (an experiment tried in Senegal and Nigeria): even though he argued against seeing traditional healers as exotic and 'peculiar African heritage' and accepted that they provided a 'useful psychotherapeutic outlet', Orley argued that they performed the same therapeutic service offered by pubs, cafes, bars and churches in Western societies. ${ }^{65}$ In other words, traditional African medicine was in no way comparable to Western psychiatric practice - 'science' and 'medicine' remained an exclusively Western domain - while African 'ethnopsychiatry' could only be linked to non-rational and non-scientific institutions. Even Yap's relativistic approach to psychiatry had its own severe limitations: Yap's conceptualization of certain non-Western phenomena as 'culture-bound syndromes' involved a pathologization of a series of non-European forms of behaviour and their translation into Western medical/psychiatric categories. Yap still prioritized the Western medical explanatory framework, and his use of the concept of 'culture-bound syndromes' to describe exclusively non-European 'exotic' phenomena and disorders set up Western illnesses as, by implication, 'culture-free'.66

It was not until the 1980s and 1990s, after the emergence of the critical discourses of the 'new cross-cultural psychiatry', that the global position of this Eurocentric psychiatric epistemology began to be challenged. In Julian Leff's caustic summary of this new anthropologically minded approach to transcultural psychiatry, it generates a view of psychiatry as a cultural product of Western societies in the same way as are the diatonic scales and Coca-Cola'. ${ }^{67}$ This culturally specific product could be exported around the world but was 'no more valid' than indigenous frameworks for understanding and treating psychological distress. In his own exposition of the critique of the 'old' transcultural psychiatry, to which Leff was responding, Roland Littlewood was significantly more subtle, arguing against global psychiatry's core assumptions that 'Western diagnostic categories were themselves culture-free entities', and that clinical research in non-European territories should begin with such Western categories and focus on exploring to what extent indigenous concepts fit with or depart from them.

While Leff, as a distinguished representative of the old approaches, believed that the 'domination of the Third World by Western biomedicine is primarily due to its manifest success in treating diseases', Littlewood objected to any attempts to order different cultures' interpretations of illness and healing in a hierarchical order, warning researchers away from assuming a 'necessary progression' from Third World categories to supposedly 'more advanced "scientific" models'. ${ }^{68}$ Even so, Littlewood confirmed that 'few medical anthropologists go so far as to maintain that the ideas developed by their informants may actually offer a more accurate understanding of events than does Western social theory' or, indeed, psychiatry. In fact, Yugoslav psychiatrist and ethnologist Caslav Hadzi-Nikolic was precisely such a voice - and it was not by accident that he came from outside the core Western centres of transcultural psychiatric knowledge. Having spent the 1980s researching concepts of mental healing among indigenous communities in the Andes, Hadzi-Nikolic concluded that the South American shamanist therapeutic systems of knowledge were intellectually superior to those of the West. In his radical and unique reading, the Western psychotherapeutic model was indeed simply another version of ethnopsychiatry,

\footnotetext{
${ }^{65}$ Orley, Culture and Mental Illness, 59.

${ }^{66}$ Ivan Crozier, 'Introduction: Pow Meng Yap and The Culture-Bound Syndromes', History of Psychiatry 29, 3 (2018), $363-85$.

${ }^{67} J u l i a n$ Leff, 'The "New Cross-Cultural Psychiatry": A Case of the Baby and the Bathwater', British Journal of Psychiatry 156, no. 3 (1990), 305-7.

${ }^{68}$ Roland Littlewood, 'From Categories to Contexts: A Decade of the "New Cross-Cultural Psychiatry"', British Journal of Psychiatry 156, no. 3 (1990): 308-27.
} 
and one that was spiritually inferior to boot, while the Western culture was only more powerful in a narrow political and military sense. ${ }^{69}$

Moreover, even before Hadzi-Nikolic's intervention, East European Marxist transcultural psychiatry produced an alternative theory of non-Western universalism, which was based on the socialist critique of colonialism and its consequences in the Global South, and on East European psychiatrists' belief that their region was fundamentally comparable to the decolonizing world. Scholarship on global transcultural psychiatry has so far completely ignored socialist and East European perspectives and contributions, even though they offered an original approach to bridging differences between the European and decolonizing worlds. In the context of the Cold War and in the midst of decolonization, socialist psychiatrists and anthropologists from Eastern Europe became increasingly involved in professional networks of socialist globalization and took part in technical aid and exchanges missions in the Global South. In the course of these exchanges, socialist psychiatry contributed important and innovative perspectives to global discussions about cross-cultural definitions of mental health and disease. For Yugoslav psychiatrists, medical researchers or engineers in particular, such collaboration was planned and discussed in the explicitly anti-colonial context of non-alignment and based on ideas of solidarity, shared liberation struggle and similarity of other historical experiences. ${ }^{70}$ In that sense, East European experts had an important role to play in the emergence of a decolonized transcultural psychiatry not least because they saw themselves as promoters of a radically different social psychiatry, which was fundamentally free from any colonial influences precisely because of the socialist world's anticolonial credentials.

For one of the leading East European and Yugoslav transcultural psychiatrists, Vladimir Jakovljevic, for instance, comparisons between Africa and Eastern Europe came naturally and effortlessly, as he discussed - both obliquely and directly - similarities between sub-Saharan and Balkan 'primitivisms' and socialist revolutions. ${ }^{71}$ Jakovljevic and his colleagues functioned in an explicitly anti-colonial explanatory framework, which aimed to eliminate hierarchical political relations between Europe and the decolonizing world. It was their ambiguous geopolitical position that made this original intervention possible - they did represent the 'White' European civilization, but their own peripheral position within Europe enabled them to promote a unique platform of political and psychiatric solidarity with the decolonizing world. Just like political activists, anthropologists and artists posited that Africa and the Balkans shared a history of slavery and colonial subordination, socialist cross-cultural psychiatrists insisted on the fundamental comparability of revolutionary situations and 'revolutionary personalities' in the two regions. Jakovljevic in particular emphasized a universal theory of the relationship between sociocultural environment and individual psychopathology, which was a result of his cross-cultural research and observations in Guinea and Yugoslavia.

For socialist psychiatrists, reductively cultural explanations of differences in psychological experiences and perceptions were uncommon - instead, because of their ideological background, they maintained a steady focus on social and economic factors and institutions, and this shaped their interpretations to an important degree. In that sense, Jakovljevic concluded that it was not the assumed inherent, unchangeable and culturally determined simplicity of the mind that decided the status of mental health or illness in the African world; it was a complex web of social, political and cultural circumstances. ${ }^{72}$ In fact, 'the complexity or otherwise of abnormal mental structures depended primarily on the nature and composition of the corresponding social institutions, and not on the level of civilization, as it is commonly assumed', and Jakovljevic argued

\footnotetext{
${ }^{69}$ Caslav Hadzi-Nikolic, Kad se vidi ono sto se ne vidi: Samani i halucinogeni (Belgrade: Itaka, 2004) (reprinted).

${ }^{70}$ Catherine Baker, Race and The Yugoslav Region: Post-Socialist, Post-Conflict, Postcolonial? (Manchester University Press, 2018).

${ }^{71}$ Jakovljevic, 'Doprinos proucavanju uloge psiholoskih uticaja socio-kulturne sredine u patogenezi neuroza', 51.

${ }^{72}$ Jakovljevic., Prilozi sa socijalnu patologiju, 168.
} 
that even 'primitive' cultures could often develop highly intricate sets of social relations. ${ }^{73}$ This focus on sociological rather than exclusively cultural interpretations of mental distress was, therefore, much more in line with the above-mentioned conclusions of African and Asian transcultural psychiatrists than with those of Jakovljevic's West European colleagues.

\section{Imagining cross-cultural encounters}

Cross-cultural encounters remained one of post-colonial transcultural psychiatry's core preoccupations. At times, broader social and cultural anxieties around the cross-cultural encounter were expressed most forcefully in psychiatric discussions, and those anxieties additionally undermined the concept of psychiatric universality. In the context of such concerns, post-war transcultural psychiatry was conceived as both a facilitator of intercultural exchanges and a field which dealt with potentially disruptive consequences of cross-cultural encounters and clashes. European colonial psychiatrists argued in the early twentieth century that exposing African natives to Westernizing influences such as education or urbanization - 'acculturation' - would have negative psychological consequences, and that 'primitive' non-Europeans were racially unsuited to such alien cultural endeavours. ${ }^{74}$ Post-colonial transcultural psychiatry, on the other hand, defined the encouragement of cross-cultural dialogue as one of its core professional and political aims. The very concept of universal humanity served to smooth the progress of intercultural understanding, dialogue and tolerance.

However, the colonial conceptualizations of cultural clash left long-lasting legacies, and postwar psychiatry continued to treat cross-cultural exposures as well as cultural hybridity as likely causes of psychological breakdown and mental conflict. In fact, Carothers' interpretation of the dangers of 'detribalization' reverberated long after the end of colonial rule. For instance, in the 1950s and 1960s, a large number of leading UK psychiatrists and psychologists accepted that West African immigrants experienced particularly high rates of mental disturbances compared with the native population and other immigrants from more 'advanced' territories. In their opinion, the core reason was the immigrants' inability to adjust to the 'modern lifestyles of European civilisation'. These interpretations seemed to be in general agreement with Carothers' statements that, if Africans could not rely on the guidance and security of their traditional cultures, they were likely to suffer severe psychological consequences. As late as the 1960s British mental health professionals insisted that Nigerian students in the UK simply could not get used to the lax discipline and solitary nature of West European university studies. The UK response to this was even more in line with late-colonial explorations: both the British authorities and many psychiatrists agreed that deportations of West African immigrants with mental health issues were the optimal solution. As Matthew Heaton aptly termed it, this practice in fact amounted to 'the reinforcement of geographical and cultural barriers between the races' and gave expression to many psychiatrists' anxieties about the possibility of cross-cultural communication. ${ }^{75}$

In 1972, Ari Kiev formulated perhaps the clearest expression of this sentiment, claiming that 'while there has been little doubt about the relationship between social factors and mental illness, only in the case of Westernization of non-Western peoples has there been unanimous agreement about the effects of social phenomena on the increase of mental illness' ${ }^{76}$ In other words, 'acculturation' appeared to be dangerous only if it occurred across the North-South divide, and many in the West appeared to react to it by reinforcing divisions and separation.

\footnotetext{
${ }^{73}$ Ibid., 166.

${ }^{74}$ John Collin Carothers, 'A Study of Mental Derangement in Africans, and an Attempt to Explain Its Peculiarities, More Especially in Relation to the African Attitude to Life', East African Medical Journal 25 (1948), 197-219.

${ }^{75}$ Heaton, Black Skin, White Coats, 84-5.

${ }^{76}$ Ari Kiev, Transcultural Psychiatry (New York: Free Press, 1972).
} 
One notable exception came out of a productive collaboration between Lambo and Cornell University's famed psychiatrist Alexander Leighton - the Cornell-Aro Mental Health Research Project, which began in 1961 and, aimed to compare conceptualizations and rates of psychological distress among the Yoruba people in Nigeria and rural Canadians in the Stirling. Leighton's background was firmly in social psychiatry, and he and his research group were explicitly concerned with the effects of 'rapid social changes ... on individual and group functioning in both our society and in the under-developed parts of the world'. ${ }^{77}$ This approach was exceptionally important precisely because it was comparative: it assumed, in contradistinction to Kiev, Carothers or Leff, that significant changes in sociocultural mores affected Western societies in similar ways as they did the decolonizing world and placed Western and non-Western communities within the same framework of 'acculturation' ${ }^{78}$ Importantly, the researchers concluded that the 'prevalence of psychiatric disorder is associated with [social] disintegration rather than with cultural change as such'. Mental illness was 'brought about by disruption in human social networks rather than as the clash of cultures within an individual psyche'. ${ }^{79}$ The US-West African research team thus de-exoticized the Nigerian community and the very concept of cultural difference and made Western and non-Western forms and expressions of mental distress truly comparable - but primarily in the context of social rather than traditional transcultural psychiatry.

It was from the East again that some of the most important challenges to this thesis stemmed. Marxist psychiatry developed theories of abrupt social, political and cultural change which went beyond the pathologization of cultural clashes and viewed revolutionary transformations in the decolonizing world from a significantly more nuanced perspective. For East European experts, while modernization carried with it a possible increase in psychological suffering and disorders, it was not a failed mission: even 'primitive' African inhabitants could adapt to a more technically and culturally advanced surrounding. The socialist rendering of transcultural psychiatry predicted ultimately positive outcomes of the momentous social and political transformations of subSaharan Africa (as well as, by extension, the socialist bloc). Cultures and societies could, under propitious circumstances, make revolutionary leaps in their own development and progress: according to Vladimir Jakovljevic, 'our experiences have clearly demonstrated that a primitive personality, who is young and capable enough, can successfully integrate in a technically and culturally developed environment, even though that integration might be accompanied by temporary mental disorders' ${ }^{80}$

Moreover, Jakovljevic criticized those interpretations of mental illness which disregarded the creative and revolutionary potential of conflicts between individuals and their social environment: 'socially caused conflicts might constitute a progressive factor in the development of a society' and lead to 'revolutionary resistance against the social organisation or structure'. While a discord or conflict between an individual and her social/cultural environment might lead to mental pathology and personality deviation, pathological or pathogenic sociocultural factors did not necessarily cause psychological disorders, if a robust individual in an abnormal society found ways to overcome or affect the existing circumstances. Quite to the contrary, a 'conformist adaptation of an individual to an abnormal social environment might lead to even more fundamental form of [psychological] abnormality....'

Mental pathology developed if (reactionary) individuals clashed with the cultural and social norms of a progressive society, but if a similar conflict occurred in a reactionary setting, it was not necessarily a sign of an abnormal personality. If the person in question could not adapt to the anachronistic or 'decadent' demands of a non-progressive cultural environment, such

\footnotetext{
${ }^{77}$ The Cornell Programme in Social Psychiatry, $1^{\text {st }}$ Annual Report, 30 June 1959, 15.

${ }^{78}$ Alexander H. Leighton. 'The Stirling Country Study, Some Notes on Concepts and Methods', Proceedings of the Annual Symposium of the American Psychopathological Association (February 1959).

${ }^{79}$ Heaton, Black Skin, White Coats, 68.

${ }^{80}$ Jakovljevic, Prilozi za socijalnu patologiju, 167.
} 
conflicts could be constructive or progressive in a revolutionary sense. In fact, such intra-psychic conflicts need not lead to mental illness at all and might even result in the 'growth of personality and society, which happens precisely as a consequence of ever more complex internal conflicts and new solutions built into that society by the personality [in question]'. On the other hand, 'absolute social adaptation to anachronistic and obsolete forms of sociability would necessarily impoverish and alienate the individual' and possibly push them into difficult neurotic disorders. ${ }^{81}$ The creative potential embedded in social and political conflicts in certain types of societies, therefore, allowed both Eastern Europe and Africa to turn possible psychological disorders into productive and progressive political behaviour. Rapid cultural change, or cultural 'clashes' within Westernizing African societies, could thus produce unique 'non-conformist' personalities, whose social and political contributions would be irreplaceable, and who would be psychologically the healthiest and most stable citizens in the developing world.

Moreover, it was only in Eastern Europe that the notion of 'acculturation' in the specific context of decolonization and rapid globalization was interpreted in an explicitly positive way. For Yugoslav commentators, psychiatrists and anthropologists, for instance, it was of foremost importance to insist on the dynamic nature of African cultures and societies: writing against the idea that (sub-Saharan) African societies were static, ahistorical and marked by 'unchangeable traditions and tribal exoticism', Jakovljevic's anthropologist colleague Biserka Cvjeticanin emphasized their dynamic history and their current creative grappling with large-scale changes. Before colonial conquests, during colonial regimes and after decolonization, different African groups and societies experienced constant change both within the confines of their own borders and in contact with other cultures, so that their capability of dynamic development and transformation was in no fundamental way different from that of Western societies. ${ }^{82}$

Cvjeticanin introduced Marx's definition of acculturation - as a process of original 'creation under the pressure of novel circumstances and by no means a simple dissolution of a culture which suffered a blow from outside'. ${ }^{83}$ Moreover, Cvjeticanin was one of the very few voices who insisted that acculturation was a two-way process, which changed Western societies as well. It was no coincidence that such a voice came from Marxist Eastern Europe: this intervention meant that the influence of African (and, by extension, other non-Western) cultures on the Western world was not minuscule or non-existent. Moreover, Cvjeticanin warned that acculturation was not assimilation or a mechanical transplantation of certain traits and mores from a more developed society to a less developed one, but it meant 'transformation and creative integration'. In the course of this process, the receiving culture demonstrated its own dynamism and ability to not only adopt new elements but also change them and ensure the authenticity and continuity of its own identity. In that sense, African cultures were neither mere imitators of more developed traditions nor unchangeable/ahistorical: just like all other societies, they chose which foreign elements and cultural aspects to adopt, adapt and fit in their own existing structures, thereby producing novel (dynamic and modern) creative totalities. In this reading, the process of acculturation was fully divested of any potentially pathological effects or meanings, and nonWestern social systems were actively de-exoticized.

Therefore, in line with Jakovljevic's arguments, Cvjeticanin did not see cross-cultural exchange as necessarily disastrously disruptive - while not without problems or conflicts, rapid sociocultural change could lead to productive situations and progress. African societies were, therefore, not exhausting all their energies merely trying to catch up, while experiencing extraordinary levels of mental distress as a consequence. They were producing authentic and valuable cultural contributions in the process of their fast development and transformation.

\footnotetext{
${ }^{81}$ Jakovljevic, 'Prilog proucavanju neurotickih poremecaja', 76-7.

${ }^{82}$ Biserka Cvjeticanin, 'Kontinuitet i dinamicnost africkih kultura', Nase Teme 23, no. 3 (1979): 785-95

${ }^{83}$ Ibid., 789.
} 


\section{Conclusion}

Historical discussions of the emergence and development of post-war transcultural psychiatry and anthropology offer fresh insights into some of the most important political and social developments of the post-Second World War era. Through the prism of post-colonial global psychiatry, this article has analysed continuities and ruptures in imperial and post-imperial power relationships and intellectual frameworks, demonstrating that the normative models of race, culture and humanity were only partially reconceptualized in the second half of the twentieth century.

The article has proposed that the middle decades of the twentieth century constituted a 'great psychiatric moment': psychological and psychiatric theories and concepts were used to make sense of political ideologies, extremism, wars, economic and political institutions, and 'psy' professionals were sought to ensure success in a variety of very important political endeavours. Following decolonization, mental health paradigms and psychological explanations came to be crucial for international organizations' and activists' understanding of the rapid social, cultural and political changes in the non-Western world. Moreover, transcultural psychiatric research was considered central to exploring psychological and social possibilities for peaceful and harmonious crosscultural communication and contact.

From that moment on and throughout the second half of the twentieth century, different versions of psychiatric universalism dominated the most important discussions in the field of transcultural psychiatry. The universalism of the first generation of post-war transcultural psychiatrists, some of whom hailed from the decolonizing world as well as other non-Western territories, was, I have argued, fundamentally different from the current biomedically informed universalist framework of the global mental health movement. This early universalism served a predominantly and explicitly political purpose in the era of decolonization and major global power shifts: it openly opposed some of the core assumptions of late-colonial psychiatry, which claimed that there existed fundamental biological and cultural differences between Western (European) and nonWestern minds/brains, and interpreted these cross-cultural differences in a hierarchical - and racist - key. While critics such as Summerfield have viewed the field of global mental health as a modern form of colonialism precisely because of its universalizing tendencies, the psychiatric universalism of the 1950s and 1960s was, thus, an explicitly anti-colonial intellectual and political platform, aiming to broaden the definition and extend the boundaries of humanity, and establish the universal identity of core psychological processes, personality traits and psychopathologies across the globe.

However, this post-colonial universalism did not succeeded in overcoming some of the most important colonial tropes and conceptualizations, especially when practised by Western psychiatrists. It was marred by evolutionary thinking, which ascribed to non-Western peoples the simplicity of the mind and less sophisticated forms of psychological experiences and expressions. Moreover, despite their repeated arguments that cultural differences were simply a veneer shaping the expression - but not the universal core - of psychiatric illnesses, many transcultural psychiatrists in the second half of the twentieth century tended to formulate overly culturalist explanations of mental disorders in the decolonizing world, disregarding a variety of social, economic and political factors, and exoticizing and reifying the very idea of cultural difference in the process. At the same time, as is the case today, the transcultural psychiatric profession largely assumed that Western psychiatric diagnostic categories were universal, that is, culture-free, and (unlike nonWestern psychological concepts and categories) not rooted in specific cultural trends and influences. It was mostly psychiatrists from the decolonizing world and from socialist Eastern Europe who aimed to undermine some of these lingering colonial assumptions, offering a form of universality based on solidarity and shared social processes, and who began to propose that Western psychiatry could be one of multiple ethnopsychiatries in a global context, rather than the sole universal yardstick. 
This article has sought to highlight the central importance of the history of transcultural psychiatry for understanding the global history of the second half of the twentieth century. The new field of post-colonial psychiatry quickly became a site where the very definition of humanity was being debated, and leading 'psy' professionals launched a search for a universal cross-cultural model of the human mind. Transcultural psychiatry aimed to intervene in some of the most important political debates of the time - on the meaning of 'world citizenship' and 'universal civilisation' - and made crucial contributions to political discussions about post-war reconstruction, migration, decolonization and plans for global peace. The article has also argued that transcultural psychiatric debates were essential to the emergence and development the idea of post-war universalism, which has recently been researched in the context of human rights discourses and international relations. In that sense, these psychiatric developments are relevant beyond the history of psychiatry and shed crucial light on a number of social, cultural and political global trends in the second half of the twentieth century.

Ana Antić is a professor (MSO) of European history at the University of Copenhagen. She currently leads a research project dedicated to the history of transcultural psychiatry, titled 'Decolonising Madness', and is the author of Therapeutic fascism: Experiencing the violence of the Nazi New Order (OUP, 2017).

Cite this article: Antić A. 2022. Decolonizing madness? Transcultural psychiatry, international order and birth of a 'global psyche' in the aftermath of the Second World War. Journal of Global History 17: 20-41, doi:10.1017/S1740022821000115 